\title{
Studying the Effect of Managerial Executive Competencies on Marketing Effectiveness in Firms
}

\author{
Dr. Fariddeddin Allameh Haery \\ Department of Management and Accounting, Mobarakeh Branch, Islamic Azad University, \\ Mobarakeh, Iran \\ Dr. Mojtaba Aghajani \\ Department of Management and Accounting, Mobarakeh Branch, Islamic Azad University, \\ Mobarakeh, Iran \\ Mandana Bahrami \\ Department of Management and Accounting, Mobarakeh Branch, Islamic Azad University, \\ Mobarakeh, Iran \\ DOI: 10.6007/IJARBSS/v3-i11/355 URL: http://dx.doi.org/10.6007/IJARBSS/v3-i11/355
}

\begin{abstract}
The major purpose of the current study was studying the effect of managerial executive competencies on marketing effectiveness in firms on customer philosophy, integrated marketing efforts, marketing information, market orientation and operational efficiency. The statistical population included seventy marketing managers of a food industry in Jey township located in Isfahan that the whole population was studied due to the fact that the statistical population was limited. So no sampling was needed. Questionnaire was used to collect the required data that contained 38 questions about research variables. Construct validity was used to investigate validity of the questionnaire and the obtained results revealed that the applied questionnaire had a suitable validity. The reliability was calculated by means of Cronbach's alpha coefficient which was equal to 0.897 for the whole questionnaire. It was an acceptable coefficient that confirmed reliability of the questionnaire. Descriptive indexes such as frequency tables and statistical diagrams were used to describe the statistical population in order to analyze research data and a general view of subjects was obtained. Then quantitative methods of statistical analysis including Kolmogoroff-Smirnoff test, correlation coefficient and structural equations modeling were used for data analysis and testing of hypotheses. To this end, SPSS 20 and LISREL software were applied. The obtained results indicate that all hypotheses were confirmed. Therefore, managerial competencies have a significant and positive effect on marketing effectiveness.
\end{abstract}

Key words: competency, executive competency, marketing effectiveness, customer philosophy, integrated marketing efforts, marketing information, market orientation, operational efficiency 


\section{Introduction}

Most companies and organizations have paid attention in recent years to subjects such as organizational change, performance improvement, employee development, succession plan and so on by implementing competency model-making plans to match managers and employees' performance with their job needs. The term competency has mainly been focused to help the organization confront with the changing environment and the need to merge human resources strategy of the organization with corporate strategy.

Nowadays, role of competent managers in pursuing purposes of the organization is not unknown. Given that organizations are faced with the global economy and future dynamic conditions they will need managers who have more complicated skills. Hence, organizations try to establish a learning and knowledge-creation approach through which future managers become more potent, talented and competent than the current ones. Thus the studies about establishment of competency principles in managers are increasing.

Importance of the status and role of managers as major designers of the organization is known to all at present. On the other hand, it must be considered that the issue of competency has become one of the important and interesting subjects of organizational societies due to its importance in management success. Considering this, the present study investigates the effect of managerial competencies on marketing effectiveness.

\section{Managerial competencies \\ Definitions of managerial competencies}

"Competency" is a combination of motivation, expertise, knowledge and social role and ethical characteristics that is originated from the scope of human resources management. Various opinions and translational failure have been led to dispersion of literature regarding human resources management especially meritocracy. One of the main reasons of obscurity of the concept of competency nowadays is representing different definitions and lack of distinction between the two concepts of competency context and competencies related to people. Competency context illustrate that group of activities in which the person has competency while competencies related to people are sum of characteristics that enable the person to be competent in a specific field. Indeed competency context are often based on job, while competencies are mainly based on people (Dehghanan, 2007).

\section{Components of competency}

Each major class of competencies contains a group of competencies that are often related to each other conceptually. Competencies in each class are associated theoretically (by means of a theory or based on a specific theoretical framework) or experimentally. Managerial competencies in this survey were studied from Boyatzis viewpoint.

\section{Executive competency}

In the approach known as the English approach competency indicates knowledge and skill. Executive competency contains knowledge and skills that include tendency towards productivity and paying attention to the effect of productivity, diagnostic utilization of concepts, conceptualization, self-confidence, using face-to-face presentations, group process management, using the power of socialization and objective understanding. Therefore, the English approach reveals that utilization of knowledge and skills as well as an extensive range of 
personal effectiveness characteristics required to perform a task are very effective (Rezayat et al., 2012).

In this method quality and performance standard are used to define competency. Basic level and performance are defined by formulation of standards in order to create a quality standard so that people can reach that level (Gladson \& Ahayzo, 2011).

Productivity is maximization of using of resources, human force and schemes scientifically in order to decrease the costs and satisfy employees, managers and consumers. Other definitions have defined human force productivity as maximum suitable utilization of human force in order to move towards purposes of the organization in the shortest time and with minimum cost (Ostadzade, 2009).

Process of conceptualization includes transparency of our understanding from things the concept indicates. Skills such as classification, proposing a definition, discovering other ways and distinguishing the differences in terms of degree and type are nourished in conceptualization skill. Socialization means to adapt with the society and familiarization with it. In sociology this concept is applied to a process through which people achieve some characteristics which merits their membership in the society. In other words, socialization is a kind of social interaction process through which the individual learns the norms, values and other social, cultural and political elements existing in the group or his/her surrounding environment, internalizes them and unifies them with his/her personality (Salimi \& Davari, 2007).

\section{2-3 Effectiveness}

\section{2-3-1 Definition of effectiveness}

One of the indexes of success measurement in each organization is the amount of purposes realized by the organization. Success of any organization is determined given to the organization itself which has been introduced as effectiveness in management literature. Indeed, effectiveness is the degree that the organization achieves its intended purposes (Robbins, 2007).

First, purposes must be defined to measure effectiveness in any organization. Then programs are compiled for their realization and afterwards the programs are implemented. Finally, the obtained results are compared with pre-determined purposes. Realization degree of purposes in any organization shows effectiveness level of that organization. The important point in determining the effectiveness level of each organization is that purposes which have been defined should be comparable with the obtained results. One of the prerequisites of this issue is that purposes which are determined in advance should be measurable (Fathi et al., 2008). 


\section{Theoretical framework}

Marketing effectiveness Managerial competencies

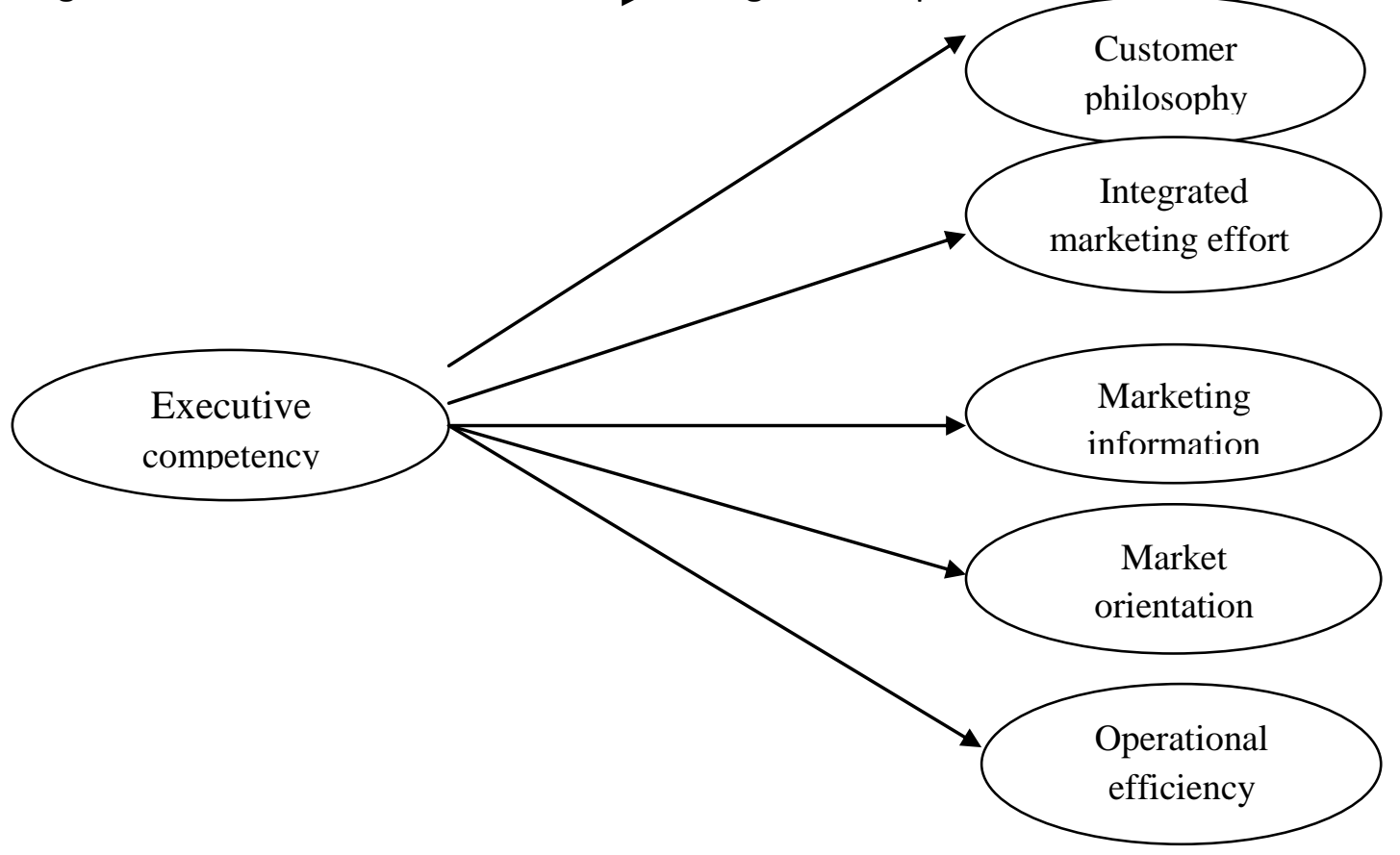

Figure 1-1 Theoretical framework of the survey (Gladson \& Ahayzo, 2011)

\section{Hypotheses}

Managerial executive competencies have a significant effect on customer philosophy.

Managerial executive competencies have a significant effect on integrated marketing effort.

Managerial executive competencies have a significant effect on marketing information.

Managerial executive competencies have a significant effect on market orientation.

Managerial executive competencies have a significant effect on operational efficiency.

\section{Methodology}

The statistical population included seventy marketing managers of a food industry in Jey township located in Isfahan. No sampling was needed due to the limited numbers The required information was collected through historical study and questionnaire. Content validity was used to measure validity of the questionnaire. Reliability of the questionnaire was calculated using Cronbach's alpha. To this end, a pilot study was conducted through distributing 30 questionnaires among the managers.

\section{Descriptive indexes related to thirty pilot samples}

Table 1-

\begin{tabular}{|c|c|c|c|}
\hline Variance & Standard deviation & Mean & Sample number \\
\hline 0.035 & 0.188 & 3.46 & 30 \\
\hline
\end{tabular}

Cronbach's alpha coefficient of pilot sample for the whole questionnaire was calculated equal to 0.897 . 
Descriptive indexes such as frequency tables and statistical diagrams were used to describe the statistical population for data analysis and a general view of subjects was obtained. Then quantitative methods of statistical analysis including Kolmogoroff-Smirnoff test, correlation coefficient and structural equations modeling were used to analyze the data and test the hypotheses. To this end, SPSS 20 and LISREL software were utilized.

Figure 5-4 T-coefficients in path analysis of structural equation

Figure 6-4 Path coefficients in path analysis of structural equation

Table 2- Direct relations of path analysis of structural equation

\begin{tabular}{|l|l|c|c|l|}
\hline \multicolumn{1}{|c|}{$\begin{array}{c}\text { The effective } \\
\text { construct }\end{array}$} & \multicolumn{1}{|c|}{$\begin{array}{c}\text { The affected } \\
\text { construct }\end{array}$} & Path coefficient & $\mathrm{t}$ & \multicolumn{1}{|c|}{ Test result } \\
\hline $\begin{array}{l}\text { Executive } \\
\text { competencies }\end{array}$ & $\begin{array}{l}\text { Customer } \\
\text { philosophy }\end{array}$ & 0.73 & 5.19 & $\begin{array}{l}\text { Rejecting the null } \\
\text { hypothesis }\end{array}$ \\
\hline $\begin{array}{l}\text { Executive } \\
\text { competencies }\end{array}$ & Integrated efforts & 0.32 & 2.58 & $\begin{array}{l}\text { Rejecting the null } \\
\text { hypothesis }\end{array}$ \\
\hline $\begin{array}{l}\text { Executive } \\
\text { competencies }\end{array}$ & $\begin{array}{l}\text { Marketing } \\
\text { information }\end{array}$ & 0.41 & 3.57 & $\begin{array}{l}\text { Rejecting the null } \\
\text { hypothesis }\end{array}$ \\
\hline $\begin{array}{l}\text { Executive } \\
\text { competencies }\end{array}$ & $\begin{array}{l}\text { Market } \\
\text { orientation }\end{array}$ & 0.56 & 5.39 & $\begin{array}{l}\text { Rejecting the null } \\
\text { hypothesis }\end{array}$ \\
\hline $\begin{array}{l}\text { Executive } \\
\text { competencies }\end{array}$ & $\begin{array}{l}\text { Operational } \\
\text { productivity }\end{array}$ & 0.38 & 3.41 & $\begin{array}{l}\text { Rejecting the null } \\
\text { hypothesis }\end{array}$ \\
\hline
\end{tabular}

\section{Hypotheses}

1- Managerial executive competencies have a significant effect on customer philosophy.

The effect of managerial executive competencies on customer philosophy was calculated equal to 0.73 that $t$-value for the calculated parameter reveals that amount of t-absolute value was more than 1.96, thus null hypothesis is rejected and alternative hypothesis is accepted. It means that there is a significant relation between the two variables of managerial executive competencies and customer philosophy.

2- Managerial executive competencies have a significant effect on integrated marketing effort. The effect of managerial executive competencies on integrated marketing efforts was calculated equal to 0.32 that $\mathrm{t}$-value for the calculated parameter reveals that amount of $\mathrm{t}$ absolute value was more than 1.96, thus null hypothesis is rejected and alternative hypothesis is accepted. It means that there is a significant relation between the two variables of managerial executive competencies and integrated marketing efforts.

3- Managerial executive competencies have a significant effect on marketing information.

The effect of managerial executive competencies on marketing information was calculated equal to 0.41 that $t$-value for the calculated parameter reveals that amount of $t$-absolute value was more than 1.96, thus null hypothesis is rejected and alternative hypothesis is accepted. It 
means that there is a significant relation between the two variables of managerial executive competencies and marketing information.

4- Managerial executive competencies have a significant effect on market orientation.

The effect of managerial executive competencies on market orientation was calculated equal to 0.56 that $\mathrm{t}$-value for the calculated parameter reveals that amount of t-absolute value was more than 1.96, thus null hypothesis is rejected and alternative hypothesis is accepted. It means that there is a significant relation between the two variables of managerial executive competencies and market orientation.

5- Managerial executive competencies have a significant effect on operational efficiency.

The effect of managerial executive competencies on operational efficiency was calculated equal to 0.38 that $\mathrm{t}$-value for the calculated parameter reveals that amount of $\mathrm{t}$-absolute value was more than 1.96, thus null hypothesis is rejected and alternative hypothesis is accepted. It means that there is a significant relation between the two variables of managerial executive competencies and operational efficiency.

\section{Goodness of fit tests}

The model's total goodness of fit with observed data can be estimated through various methods after the model is determined. There are several indexes to measure the model's goodness. It is usually adequate to use three to five indexes to confirm the model.

Table 3- Goodness of fit indexes of structural equations model

\begin{tabular}{|l|c|c|c|c|c|c|c|}
\hline \multicolumn{1}{|c|}{ Model } & Chi- square & P & RFI & RMR & GFI & AGFI & RMSEA \\
\hline $\begin{array}{l}\text { The default } \\
\text { model }\end{array}$ & 2067.7 & 0.087 & 0.73 & 0.069 & 0.62 & 0.57 & 0.062 \\
\hline
\end{tabular}

RFI index: Value of this index changes between zero and one so that values close to one are interpreted as better goodness of data with the model. In this survey RFI= 0.73 that shows the model has a suitable goodness.

P-value performs the test that goodness of the model is suitable. Given that $p$-value $=0.087$ it shows suitable goodness of model. RMR index is changeable for measurement of average residues just in association with variances and co-variances. Whatever this standard is smaller (closer to zero) it shows better goodness of the model. In this survey RFI= 0.069 that shows the model has a suitable goodness.

GFI and AGFI indexes: Whatever GFI and AGFI indexes are closer to 1 , goodness of fit of the model with observed data is more. In this survey $\mathrm{GFI}=0.62$ and $\mathrm{AGFI}=0.57$ that show the model has a suitable goodness, i.e. the model is confirmed.

RMSEA index for models which have a suitable goodness is less than 0.05 . The higher values up to 0.08 show a reasonable error for proximity in the statistical population. The models in which the goodness index is equal to 0.1 or more have a weak goodness. Thus this model has a moderate goodness given that RMSEA is equal to 0.067 . Considering the presented indexes it can be stated that the model has a relatively good fit.

\section{Ranking of variables}

Mean rank of the variables under study are compared using Friedman test in this section. Testing of the assumption is as below: 
HO: Mean rank of variables is equal.

$\mathrm{H} 1$ : At least one pair of ranks has a significant difference with each other.

According to results of Table 4, importance of factors or variables under study is not the same in respondents' viewpoint, because its significance level is less than 0.05 . Thus, mean rank of various dimensions of the survey is not equal.

Table 4- Results of Friedman test

\begin{tabular}{|l|c|}
\hline Number & 61 \\
\hline Chi-square coefficient & 90.036 \\
\hline Degree of freedom & 7 \\
\hline Significance level & 0.000 \\
\hline
\end{tabular}

Mean rank of these factors is shown in Table 4. Mean rank of executive competency is more than other factors and mean rank of marketing information is less than others.

Table 5- Mean rank of factors

\begin{tabular}{|l|l|}
\hline Mean rank & \\
\hline Customer philosophy & 4.60 \\
\hline Integration & 3.77 \\
\hline Marketing information & 2.70 \\
\hline Market orientation & 2.79 \\
\hline Operational efficiency & 3.78 \\
\hline Executive competency & 5.15 \\
\hline
\end{tabular}

\section{Variance analysis test}

Variance analysis test is used to study whether variables are the same or different in various aspects in the statistical population under study and based on demographic characteristics of respondents. Thus, the following statistical assumption is evaluated:

$\left\{\begin{array}{l}\mathrm{H} \\ \mathrm{H}\end{array}\right.$ H0: Means of variables are equal.

$\mathrm{H} 1$ : At least one pair of variables has a significant difference with each other.

\section{Conclusion}

Results of the present survey reveal that managerial competencies have a significant effect on organizational effectiveness. Also results of secondary hypotheses show that managerial executive competencies have had a positive and significant effect on customer philosophy, integrated marketing efforts, marketing information, market orientation and operational efficiency.

Results of secondary hypothesis one show that managerial executive competencies have a positive and significant effect on costumer philosophy. Therefore, it is recommended to perform necessary actions to improve managerial executive competencies in order to improve customer philosophy. Executive competency includes knowledge and skills among which we can refer to tendency towards productivity and paying attention to the effect of productivity, 
diagnostic utilization of concepts, conceptualization, self-confidence, using face-to-face presentations, group process management, using the power of socialization and objective understanding. Hence, it is recommended to improve elements of managerial executive competencies such as productivity and paying attention to the effect of productivity, diagnostic utilization of concepts, conceptualization, self-confidence, using face-to-face presentations, group process management, using the power of socialization and objective understanding to be expected that their attention and emphasis on customer philosophy are improved.

The results of hypothesis two indicate that managerial executive competencies have a positive and significant effect on integrated marketing efforts. It is, thus, recommended to improve productivity and paying attention to the effect of productivity, diagnostic utilization of concepts, conceptualization, self-confidence, using face-to-face presentations, group process management, using the power of socialization and objective understanding so that their integrated marketing efforts can be improved. For instance, by improving of group process management and using face-to-face presentations it can be expected to increase their integrated marketing efforts.

As the results obtained from hypothesis three show managerial executive competencies have a positive and significant effect on marketing information. Hence it can be stated that enhancement of managerial executive competencies can improve managers' marketing information. It is recommended to improve managers' marketing information by improving productivity and paying attention to the effect of productivity, diagnostic utilization of concepts, conceptualization, self-confidence, using face-to-face presentations, group process management, using the power of socialization and objective understanding among the managers. For instance, managers' marketing information can be expected to increase by increasing of their socialization power.

The results obtained from hypothesis four illustrate that managerial executive competencies have a positive and significant effect on market orientation. Therefore, it can be stated that managerial executive competencies can improve managers' market orientation. It is recommended to increase productivity and paying attention to the effect of productivity, diagnostic utilization of concepts, conceptualization, self-confidence, using face-to-face presentations, group process management, using the power of socialization and objective understanding in order to improve market orientation among the managers. As it was mentioned in chapter one, market orientation in a business unit is a degree that the business unit has gained the information from customers and uses them; compiles a strategy to realize customers' needs and applies that strategy in order to respond to customers' needs and demands. So it can be expected to improve managers' market orientation by increasing of managerial executive competencies (through increasing of productivity and paying attention to the effect of productivity, diagnostic utilization of concepts, conceptualization, self-confidence, using face-to-face presentations, group process management, using the power of socialization and objective understanding).

As the results of hypothesis five illustrate managerial executive competencies have a positive and significant effect on operational efficiency. Thus it is recommended that managers' operational efficiency can be improved by improving their managerial executive competencies (through increasing of productivity and paying attention to the effect of productivity, diagnostic utilization of concepts, conceptualization, self-confidence, using face-to-face presentations, 
group process management, using the power of socialization and objective understanding). Therefore, it can be expected that managers' operational efficiency (i.e. the manager provides maximum output by spending minimum resources (input) by means of optimal methods) is increased if they enjoy executive competencies.

\section{References}

Dehghanan, H. (2008). Management based on competency. Journal of Majlis and Research, 13 (53), Research Center of the Islamic Consultative Assembly, pp. 45-53

Fathi, N; Shabani Ravari, A and Alirezaee, M. (2008). "Scientific and empirical model of training Saipa managers in future". Nourbakhsh Publications, p. 160

N. Gladson Nwokah, Augustine I. Ahiauzu.2011. Managerial ompetencies and marketing effectiveness in corporate organizations in Nigeria. Journal of Management Development Vol. 27 No. 8, pp 858-878.

Ostadzade, M. (2009). "Effective factors on increasing or decreasing of human force productivity". Retrieved from http://www.mgtsolution.com/olib/575797670.aspx

Rezayat, GH; aminiduzi Sarkhabi, M; Kiamanmesh, E. (2012). "Architecture of competency models: Proposing a conceptual framework". Journal of Human Resources Management Research at Imam Hossein University. 3 (2), pp. 49-81

Robbins, S. (2007). "Principles of organizational behavior". Office of Cultural Studies, p. 480 Salami, R and Davari, M. (2007). "Cultural engineering and national identity in the globalization age". Monthly Journal of Cultural Engineering, Superior Council of Cultural Revolution, 10 \& 11, pp. 68-75 